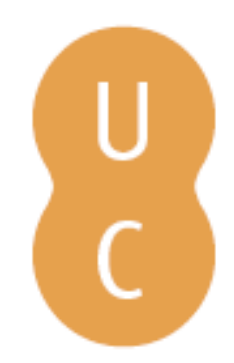

\title{
nommalina
}

Algumas notas sobre o "amor", o "desengano" e o "artifício" nas Obras Métricas (1665) de D. Francisco Manuel de Melo

\author{
Autor(es): $\quad$ Santos, Zulmira \\ Publicado por: Imprensa da Universidade de Coimbra; Ediciones Universidad \\ URL \\ persistente: URI:http://hdl.handle.net/10316.2/31525 \\ DOI: $\quad$ DOI:http://dx.doi.org/10.14195/978-989-26-0245-5_14 \\ Accessed : $\quad$ 26-Apr-2023 06:57:53
}

A navegação consulta e descarregamento dos títulos inseridos nas Bibliotecas Digitais UC Digitalis, UC Pombalina e UC Impactum, pressupõem a aceitação plena e sem reservas dos Termos e Condições de Uso destas Bibliotecas Digitais, disponíveis em https://digitalis.uc.pt/pt-pt/termos.

Conforme exposto nos referidos Termos e Condições de Uso, o descarregamento de títulos de acesso restrito requer uma licença válida de autorização devendo o utilizador aceder ao(s) documento(s) a partir de um endereço de IP da instituição detentora da supramencionada licença.

Ao utilizador é apenas permitido o descarregamento para uso pessoal, pelo que o emprego do(s) título(s) descarregado(s) para outro fim, designadamente comercial, carece de autorização do respetivo autor ou editor da obra.

Na medida em que todas as obras da UC Digitalis se encontram protegidas pelo Código do Direito de Autor e Direitos Conexos e demais legislação aplicável, toda a cópia, parcial ou total, deste documento, nos casos em que é legalmente admitida, deverá conter ou fazer-se acompanhar por este aviso.

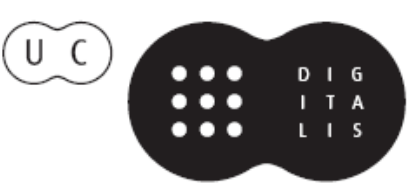


Marta Teixeira Anacleto

Sara Augusto

Zulmira Santos

Coordenação

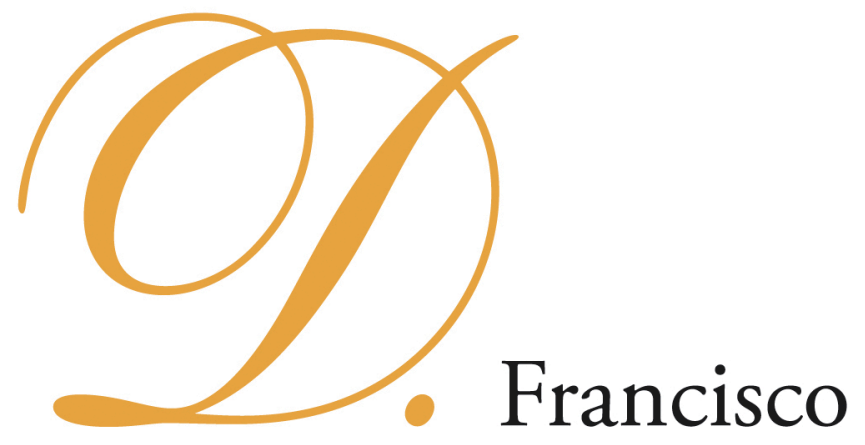

Manuel de Melo e o

Barroco Peninsular 


\title{
EDIĈ̣̃O
}

Imprensa da Universidade de Coimbra Ediciones Universidad Salamanca

\section{COORDENAÇÃo EDITORIAL}

Imprensa da Universidade de Coimbra

URL: http://www.uc.pt/imprensa_uc

Vendas online: http://www.livrariadaimprensa.com

\section{CONCEPÇÃO GRÁFICA}

António Barros

\section{REVISÃO TEXTO}

Sara Augusto

\author{
Pré-Impressão, Impressão e ACABamento \\ www.artipol.net
}

\section{IS B N}

978-989-26-0044-4 (Portugal)

978-84-7800-194-1 (Espanha)

DEPósito LEGAL

$311680 / 10$

OBRA PUBlicada COM O APOIO DE:

FCT Fundação para a Ciência e a Tecnologia

MINISTÉRIO DA CIÊNCIA, TECNOLOCIA E ENSINO SUPERIOR Portugal

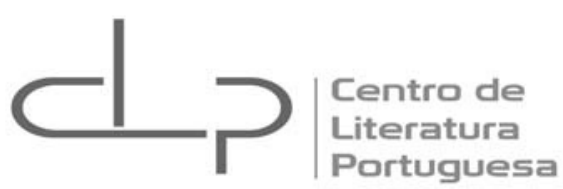

A presente publicação insere-se no Grupo "Poéticas" (coordenação de Marta Teixeira Anacleto) do Centro de Literatura Portuguesa, Unidade de I\&D financiada pela Fundação para a Ciência e a Tecnologia, ao abrigo do Programa Operacional Ciência e Inovação 2010.

(C) Agosto 2010

IMPRENSA DA UNIVERSIDADE DE COIMBRA

EDICIONES UNIVERSIDAD DE SALAMANCA 
Marta Teixeira Anacleto

Sara Augusto

Zulmira Santos

Coordenação

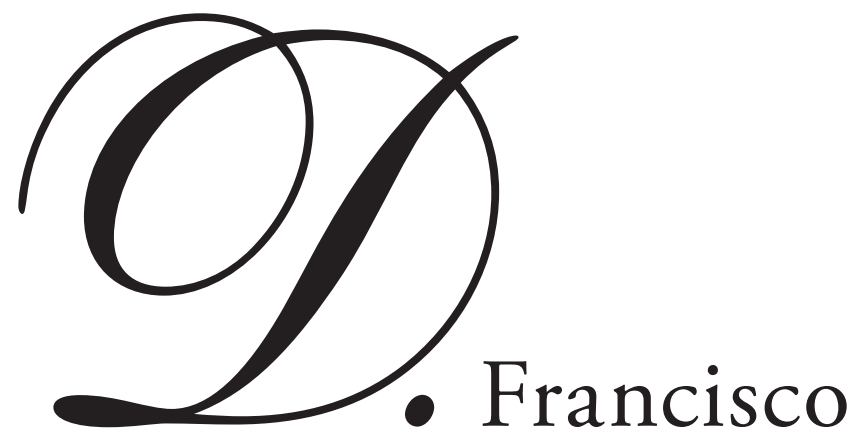

Manuel de Melo e o Barroco Peninsular

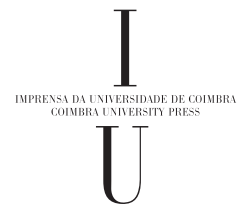


PARTE III

MODALIDADES DE ESCRITA DO BARROCO EM D. Francisco Manuel de Melo 


\section{Zulmira Santos \\ Universidade do Porto}

\section{ALGUMAS NOTAS SOBRE \\ $O$ «AMOR», O «DESENGANO»E O «ARTIFÍCIO» \\ NAS OBRAS MÉTRICAS (1665) DE \\ D. FRANCISCO MANUEL DE MELO,}

No início das "Segundas Três Musas de Melodino», na edição das Obras Métricas, de Lyon, 1665, os editores, Horacio Boissat e George Remeus, acentuavam:

Posso afirmar-vos da parte de quem o melhor sabe que, se bem o seu autor (como muitas vezes escreve) nunca de seus versos teve gosto, porque os mais foram escritos com desgosto e emendados sem tempo, todavia, se para alguns se mostrou inclinado, foi para estes, ou porque os compôs mais vizinho às últimas raias da mocidade, ou porque por isso mesmo tivessem maior desengano que artifício. Entendi vos devia fazer esta advertência, porque falta nela o autor na introdução que faz, assi às pessoas a quem dedica, como às que entrega suas Obras. Agora avisados dela, não estranheis, antes estimai a rara mudança do estilo, que de todo parece alheio, e diverso do que até agora deste autor tendes ouvido; louvável cousa sempre, ou seja abundância ou melhora, e concedida a poucos, ser grande mais que uma vez. Para o último terno castelhano vos convido, que não tardará em estampar-se. ${ }^{1}$

A passagem em causa, sobretudo pelo que se prende com a «inclinação» do autor pelas composiçóes integrantes das Segundas três Musas, ele que «nunca de seus versos teve gosto», porque compostas «às últimas raias da mocidade» ou "porque tivessem maior desengano que artifício» - D. Francisco entende-os nas Cartas Familiares como esses «versos portugueses» que «parecem escritos há duzentos anos» ${ }^{2}$ - convida à compaginação com a conhecida passagem do Hospital das Letras que brevemente evoco, na voz de Lípsio:

\footnotetext{
${ }^{1}$ Citaremos sempre pela edição das Obras Métricas (dir. por Maria Lucília Gonçalves Pires e José Adriano de Freitas Carvalho). Braga: APPCDM, 2006.

2 «Eu tenho aqui um volume de versos portugueses, e tanto, que parecem escritos há duzentos anos. Desejo estampa-los limpamente e com o meu nome, à diferença dos castelhanos, que creo sairáo à luz brevemente com algum suposto. Muito quisera que a impressão se fizesse nessa terra, mas à falta de correcção me detenho. Se a assistência de V. M. desse lugar à emenda e a alcançar o fim da obra, não me seria dificultoso mandar lá o original,
} 
as Musas são donzelas louçãs em a flor da idade porque verdadeiramente ela [a Poesia] é uma arte florida que pede sujeitos floridos em anos florescentes. ${ }^{3}$

Não vou, porém, centrar-me no desenvolvimento deste filão da ligação da praxis poética aos anos de juventude, de larga tradição secular, bastando recorrer, para atestar tal afirmação, à célebre passagem do Marquês de Santillana, no Prohemio e Carta ao Condestável D. Pedro:

Porque, señor, así como el Apóstol dize, Cum essem parvulus, cogitam ut parvulus, loquebar ut parvulus. Ca estas tales cosas alegres e jocosas andan e concurren com el tiempo de la nueva hedad de juventud, es, a saber: com el vestir, com el justar, con el dançar e con otros tales cortesanos exercícios. E asy, señor, muchas cosas plazen agora a vos que ya no plazen o no devem plazer a mí. ${ }^{4}$

No sentir dos editores, inspirado, com toda a certeza, pela opiniáo do autor, que seguiu com toda a atenção este processo editorial, os versos das «Segundas três Musas» "A Tuba de Calíope», "A Sanfonha de Euterpe» e «A viola de Talia» - teriam «maior desengano que artifício», o que poderia levar-nos a concluir, nem que seja apenas como motivo de reflexão sobre a poesia de D. Francisco, que os outros versos, de outras «musas», teriam mais «artifício» que «desengano». Aliás, na «Dedicatória que se achou com estas obras manuscritas", texto que, de resto, praticamente coincide com o de uma carta, datada de 28 de Outubro de 1648, com a indicação «A um amigo com os versos portugueses», o autor sublinha o carácter pouco «artificioso» desta produção, na moldura de uma «imitação» que o texto se encarregará de precisar:

V. S. é táo português, e táo bom português, que não enjeitará a conversação destes consoantes, $\mathrm{o}[\mathrm{s}]$ quais, ainda que meus, postos com pouco artifício e pesados em breves consideraçóes, não sei se diga que (sobre serem os mais mimosos da casa) muito se parecem com aqueles a quem quiseram imitar. ${ }^{5}$

Versos, assim, feitos "com pouco artifício», mas "pesados em breves consideraçóes», que D. Francisco integra na senda da evocação do "grave estilo de nossos antepassados», que pretende «ressuscitar»:

bem castigado, para que V. M. dispusesse sua estampa; e com ele faria ir os efeitos do seu dispêndio" (Cartas Familiares. Prefácio e notas de Maria da Conceiçáo Sarmento. Lisboa: 1980, p. 432). Ver também Antonio Bernat Vistarini, Francisco Manuel de Melo (1608-1666). Textos y contextos del Barroco peninsular. Palma: 1992.

${ }^{3}$ A. Correia de Oliveira lembra a passagem que Cervantes no Quijote dedica a este tema, apresentando a poesia e as musas como donzelas. (D. Francisco Manuel de Melo, As Segundas três Musas. Ensaio crítico, selecção e notas de A. Correia de Oliveira. Lisboa: 1945, p. 39).

${ }^{4}$ Marquês de Santillana, Comedieta de Ponza, sonetos, serranillas y otras obras. Ed. de Regula Rohland de Langbehn. Estúdio Preliminar de Vicente Beltrán. Barcelona: Crítica, 1997, pp. 12-13.

${ }^{5}$ Obras Métricas, p. 437. 
Não aquele cuja aspereza já para muitos foi desagradável, como no antigo Mena condenou o grande Sá; mas aqueloutro donde, como o diamante que reluz por entre os golpes da luva, vai cintilando por entre as frases naturais, engraçadas e facilíssimas. ${ }^{6}$

Numa leitura que presumimos que o texto suporta, até porque a argumentação ocorre repetida, seria legítimo concluir que D. Francisco entende os versos «portugueses» como menos «artificiosos», porque feitos de «frases naturais, engraçadas e facilíssimas», na imitação do "grave estilo dos nossos passados» - que a alusão a Sá de Miranda contribui para enquadrar no século $\mathrm{XVI}^{7}$ - interpretação que os editores corroboram, ao acentuarem, como no início referi, em contexto de «advertência», que os versos das «Segundas Três Musas» possuíam «maior desengano que artifício» e que, alusão não menos importante, tal se entendia como uma «rara mudança de estilo, que de todo parece alheio, e diverso do que até agora deste autor tendes ouvido». Tendo em conta que "o que até agora» se tinha ouvido só poderia ser, numa interpretação restritiva, a parte referente às primeiras três musas ou, quando muito, a edição prévia de «Las tres musas» de 1649 (Lisboa, na Oficina Craesbeeckiana, por Henrique Valente de Oliveira) que, pela coincidência textual, devem, neste enquadramento hermenêutico, funcionar como a mesma obra, as «musas portuguesas» representariam, assim, uma «mudança de estilo» concretizada em mais «desengano» que artifício», na senda da evocação do estilo dos poetas portugueses do século XVI, com toda a probabilidade, sobretudo de Sá de Miranda e de Camóes, se recordarmos que D. Francisco estava ligado por laços de amizade a dois editores do épico - Faria e Sousa e António Álvares da Cunha - e seguiu de muito perto a edição das obras do poeta da Tapada, em $1651^{8}$.

Convirá não ignorar que a configuração das Obras Métricas, na esteira de uma prática de organização dos versos que o Canzoniere de Petrarca havia divulgado, materializada, como é óbvio de diferentes e várias maneiras, parece implicar, pela ordenação paratextual, uma sintaxe narrativa que aqui se materializa numa espécie de movimento ascendente de "perfeição» de musa para musa: os dois paratextos que acompanham «Las tres musas del Melodino" anunciam - embora não tendo sido expressamente redigidos para a edição das Obras Métricas, pois que o primeiro, "Al Señor Juan Rodriguez de Vasconcelos y Sosa, embora assinado «El impressor», repete a dedicatória da edição de 1649, e o segundo, intitulado "Con el original de estos versos se halló esta carta que sirva de sú introduction", passa por ter sido aproveitado para a funçáo prologal - um programa poético que salienta a dificuldade discursiva em fazer versos, «vos sabéis cuánta sazón pide la plática de las musas [...]», «Si os dijese no hay en todo letra a mi gusto [...]», sobretudo, nas palavras de D. Francisco, em «lenguaje extrangero» que «tampoco es favorable al que compone»,

${ }^{6}$ Obras Métricas, p. 439.

${ }^{7}$ V. Maria Lucília Gonçalves Pires, «Ecos Literários nas Obras Métricas», Obras Métricas, p. XXVII.

${ }^{8}$ A. da Costa Pimpão, "A Lírica camoniana no século XVII. Faria e Sousa e Álvares da Cunha», Escritos diversos. Coimbra: Acta Universitatis Conimbrigensis, 1972; V. Aguiar e Silva, "Notas sobre o cânone da lírica camoniana (II)», Camões. Labirintos e Fascinios. Lisboa: Cotovia, 1994, pp. 73-100; Maria Lucília Gonçalves Pires, "Ecos Literários nas Obras Métricas», Obras Métricas, p. XXVII; Rita Marnoto, "O 'livro de poesia'. O cancioneiro petrarquista e a edição das Obras de Sá de Miranda de 1595», Revista Portuguesa de História do Livro, VIII, n 15. Lisboa: 2004. 
sublinhando alguma juvenil inconsciência que o teria levado a imitar o estilo «cândido de los Vegas, lo severo de los Leonardos, lo culto de los Góngoras y Hortensios». Esta interpretação permite perceber que os editores expendam sobre as «musas portuguesas» as considerações acima equacionadas. Enquanto o «estilo» das primeiras três musas seria "artificioso", o das segundas sê-lo-ia menos, "[...]consoantes, os quais, ainda que meus, postos com pouco artifício e pesados em breves consideração [...]» - por isso os editores solicitavam aos leitores que não estranhassem antes estimassem a diferença - e, enquanto estas teriam mais "desengano», as terceiras, «El tercer coro de las musas del Melodino», apelidadas pelo editor de «joya de mi oficina», embora escritas pelo mesmo autor «Escribiolas el próprio Melodino y con la mesma pluma, mas tan superiormente cortada [...]» - atingiriam tal grau de perfeição que parece que todas as outras teriam servido de ensaio para chegar à redacçáo destas ${ }^{9}$. A existência de uma sintaxe paratextual pode, assim, explicar que o texto da "Epístola a los lectores por un aficionado del autor y del estudio poético», que as antecede, subscrito por «El Cándido, Académico Generoso», nome usado na Academia dos Generosos por Frei André de Cristo, enfatize «los conceptos sutiles, las locuciones altas, las voces selectísimas que no podrán escurecer los más desaficionados, si hay algunos $[\ldots]^{10}$, ostentando um conceito de poesia tributário da agudeza verbal e de um sábia e "discreta» forma de exercer e exercitar a capacidade de «engenho» ${ }^{11}$.

Aliás, esta espécie de «Prólogo» ecoa, de algum modo, as palavras, ou as preocupaçôes, do livreiro Estêvão Lopes, ao editar, em 1598, pela segunda vez, as Rimas de Camóes. Aqui, apelando à qualidade poética de um texto produzido por "admiravel engenho", o editor enfatiza o quanto «espanta a agudeza de seus côceitos, como obriga propriedade das palavras, como enleva o encarecimento das razóes. Que alteza tem de sentẽças, que metaphoras, que hipérboles, que figuras tã Poéticas?»" ${ }^{12}$, visando não apenas a "novidade» da presença de composiçóes que justificavam a indicação "Accrescentadas nesta segunda impressão", mas também o enaltecimento de uma técnica retórico-compositiva que elevava Camóes ao estatuto de autor modelar. Talvez não seja sem razão que Frei André de Cristo evoca, no final dos comentários sobre o virtuosismo poético de D. Francisco Manuel de Melo, o verso de Camóes: «Porque quem não sabe a arte não a estima» ${ }^{13}$, aludindo a uma espécie de

\footnotetext{
${ }^{9}$ «Son otras las obras que ofrezco a V. Excelencia, mas no es el autor otro ni otro el animo que se las dedica. Escribiolas el proprio Melodino y con la mesma pluma mas tan superiormente cortada que, según el juicio de los práticos, parece que el poeta solo para escribir estas ha escrito las otras». Obras Métricas, p. 804.

${ }^{10}$ Obras Métricas, p. 805.

${ }^{11}$ Permitimo-nos remeter para Zulmira C. Santos, «O conceito de poesia de D. Francisco Manuel de Melo", Obras Métricas, pp. XXIX-XXXVI.

${ }^{12}$ Rimas de Luís de Camóes acrescentadas nesta segunda impressão. Dirigidas a D. Gonçalo Coutinho. Em Lisboa, por Pedro Crasbeeck, Anno de MDXCVIII. A custa de Estêvão Lopes mercador de libros (cito pela rep. fac-similada da ed. de 1598, com Estudo Introdutório de Vítor Manuel de Aguiar e Silva. Braga: Universidade do Minho, 1980, «A D. Gonçalo Coutinho».

${ }^{13}$ Obras Métricas, p. 809: "Con lo que solo acreciento que estimes este libro, porque parezcas persona digna de estimación, según la sentencia de nuestro Camoens: Porque quem não sabe a arte não a estima». Lucília G. Pires, «Ecos literários nas Obras Métricas», Obras Métricas, p. XXVI.
} 
«consciência» técnica que não é para todos, no sentido algo exclusivo, em que, como dizia D. Francisco, «não fiz livro em muitas horas para se ler em ũa hora» ${ }^{14}$.

A função prologal destes paratextos parece, assim, comportar uma funcionalidade específica que se orienta para a "captatio» do leitor, evidenciando, pelas diferenças anotadas pelos editores através dos testemunhos do autor e de palavras autorizadas como as de André de Cristo, uma competência "poética» apta para gerir e harmonizar um leque de vozes poéticas e literárias de cariz diferenciado, capaz de encontrar a «mutua correspondência entre los metros, estilos e asuntos» ${ }^{15}$.

\section{"Artifício», «desengano» e «amor»}

A lição dos paratextos permitiria, então, concluir que se as primeiras três musas possuiriam mais «artifício», as segundas mais «desengano» e menos "artificio», porque feitas de "frases naturais, engraçadas e facilíssimas» e as terceiras seriam uma espécie de culminar de perfeição de prática poética, revelando, assim, um autor capaz de sintetizar diferentes «estilos» e uma obra preparada para agradar a diferentes públicos, não só de diversas naturezas em termos de erudiçáo, mas, quem sabe... talvez, também, em termos de nacionalidades, procurando conferir às Obras Métricas potencialidades de leitura que ultrapassavam fronteiras para além das ibéricas, como seria óbvio ao tempo e natural num autor táo «cosmopolita» como D. Francisco Manuel de Melo ${ }^{16}$.

Procurando reflectir sobre as implicaçóes que o «artifício» e o "desengano» eventualmente comportam no tratamento da temática amorosa, haverá que ter em conta que, se pensarmos nas composiçóes que expressamente desenvolvem o amor como tema maior, encontraremos alguma concentraçáo nas primeiras três musas que integram, justamente, na primeira, «El arpa de Melpomene», um conjunto de "Sonetos amorosos» ${ }^{17}$, na segunda, "La Cítara de Erato», um grupo de «romances» também assim denominados ${ }^{18}$ e na terceira, "La tyorba de Plymnia», um breve grupo de "madrigais» ${ }^{19}$, para além de outras composiçôes mais esparsas que adiante se examinarão, enquanto as segundas apresentam apenas em «A Tuba de Calíope» - que é por sua vez a primeira da segunda parte - um conjunto mais disperso de sonetos assim apelidados (distribuídos com outros ditos «moral», «laudatório»...) e as terceiras, «El Tercer Coro», diluem, sobretudo na sétima, «La lira de Clío», que é, justamente, a primeira da última parte, um grupo de sonetos de temática amorosa, não

${ }^{14}$ D. Francisco Manuel de Melo, Cartas Familiares, 24 de Março de 1650 (prefácio e notas de Maria da Conceiçấo Sarmento. Lisboa: 1980).

${ }^{15}$ Obras Métricas, p. 807.

${ }^{16}$ Giacinto Manupella, «Acerca do cosmopolitismo intelectual de D. Francisco Manuel de Melo». Sep de Brasília. Coimbra: 1960, vol. IX; Maria de Lurdes Correia Fernandes, «Des sociabilités qui surmontent les distances. Autour du réseau dês relations intelectuelles de Francisco Manuel de Melo» in Arquivos do Centro Cultural Português. Paris-Lisboa: 2005, pp. 33-44.

${ }^{17}$ Obras Métricas, pp. 53-94.

${ }^{18}$ Obras Métricas, pp. 190-216. «Amorosos. Amor, miedo, y ocasión».

${ }^{19}$ Obras Métricas, pp. 300-304. 
directamente identificados como tal, mas submetidos a uma epígrafe que contribui para a sua inclusão em tal «apartado». Haverá que acautelar a evidência de que a temática amorosa, entendida em sentido geral - a beleza feminina, por exemplo...-, se dissemina por toda a obra, umas vezes mais em contexto moral ou moralizante outras de forma circunstancial ${ }^{20}$. Aqui, com muitas limitaçóes, procuraremos equacionar alguns comentários reflexivos no campo da articulação das composiçôes que, de um modo ou de outro, isto é, pelo título ou pela epígrafe, se apresentam nas Obras Métricas como expressamente «sobre o amor», com a forma como cada grupo de musas se apresenta ao leitor nos termos paratextuais que acima examinámos.

Voltando ao «artifício» e ao «desengano» - duas palavras-chave da estética barroca - cuja prevalência os editores entendem como marca da distinção entre as segundas e as primeiras três musas, deve assinalar-se que o "artifício» releva essencialmente do universo formal, marcado pelo investimento numa técnica retórico-compositiva que se concretiza «em altos conceitos, sólidas doutrinas, /sutis ideias, frases elegantes/raras sentenças, flores peregrinas/vivos exemplos regras abundantes $»^{21}$, para citar apenas uma das muitas passagens em que a obra de D. Francisco, por alheia ou própria voz mergulha nesta questão, enquanto o «desengano» se inscreve predominantemente em área temática. E se o «desengano» se foi tornando, na poesia de finais do século XVI, um tema constante que a produção discursiva posterior, em prosa ou em verso, quase transformou em presença obsessiva, ao «artifício» reservam as reflexóes teóricas do tempo, nem sempre coincidentes, nem em cronologias nem em juízos - de Gracián ${ }^{22}$ a Tesauro ${ }^{23}$ ou, até em data anterior, a Peregrinii ${ }^{24}$-, um lugar especialmente importante, já amplamente demonstrado ${ }^{25}$. Gracián cita em várias ocasióes a importância estruturante do "artifício», Tesauro e Peregrini reconhecem-lhe uma função fundamental no contexto das «argutie humane» ${ }^{26}$, se bem que Peregrini alerte para o uso «excessivo» «delle acutezze»" ${ }^{27}$. Deste ponto de vista, D. Francisco, poeta e homem do seu

${ }^{20}$ Como, por exemplo, na "Viola de Talia» as "Quintilhas XXV», Foi travesso assunto académico galantear com uns olhos que choravam e riam juntamente. Obras Métricas, pp. 714-715.

${ }^{21}$ "Banquete métrico», Obras Métricas, p. 792.

${ }^{22}$ Baltasar Gracián, Agudeza y Arte de Ingenio [1648]. Ed. de Ceferino Peralta, J. M. Ayala y José Ma Andreu. Zaragoza: PUZ, 2004.

${ }^{23}$ Emanuele Tesauro (1592-1657), Il Cannocchiale aristotelico o sia idea dell'arguta et ingeniosa elocutione che serve a tutta l'arte oratória, lapidaria e simbólica, esaminata co' Principii del divino Aaristotele. 1654.

${ }^{24}$ Matteo Peregrini (c1595-1652), Delle acutezze, che altrimenti spiriti, vivezzi, e concetti volgarmente si appellano. Genova: per Gio. Maria Farroni, Nicolò Peasagni \& Pier Francesco Barbieri, 1639. Citarei pela edição prepara da por Erminia Ardissino. Torino: Ed. Res, 1997.

${ }^{25}$ Apenas como exemplo de uma ampla bibliografia, Andrea Battistini, Il Barocco. Cultura, miti, immagini. Roma: Salerno Editrice, 2000; Aurora Egido, De la mano de Artemia. Literatura, emblemática, Mnemotecnia y Arte en el siglo de Oro. Barcelona: Ed. UIB, 2004.

${ }^{26}$ Emanuele Tesauro (1592-1657), Il Cannocchiale aristotélico. 1654, pp. 82-83. Cito pela reprod. anast. da 5a impressão. Torino: 1670, preparada pela Editrice Artística Piemontese, 2000. M. Peregrini: «come il translato, il noema, l'anfibologia e la finzion palese sieno gli artificii principali onde si formano i fonti delle acutezze (Delle Acutezze, cap. VIII, p. 81)

27 «Propone venticinque cautele per l'uso delle acutezze», Matteo Peregrini, Delle acutezze, che altrimenti spiriti, vivezzi, e concetti volgarmente si appellano, cap. XII, pp. 124-154. 
tempo, não ignora o fascínio, salientado por Tesauro, ao discorrer sobre as potencialidades da metáfora, de «vedere in un vocabulo solo, un pien teatro di meraviglie» ${ }^{28}$.

$\mathrm{O}$ «desengano», como prática «temática» que o aparato paratextual associou sobretudo às musas portuguesas, haverá que lê-lo nas muitas composições em que o poeta não apenas dá conta de apontamentos circunstanciais das suas vivências quotidianas, acentuando formas de «conviavilidade» cortesás - do agradecimento, ao pedido, à celebração de nascimentos pontuadas por um conjunto de rituais de corte que, traduzindo o seu envolvimento nesse quotidiano, deixam, no mesmo movimento, marcas de alguma amargura, sublinhando a importância da salvação e a efemeridade da vida terrena ${ }^{29}$. São muitas as composiçóes que, nas «Segundas três musas», incorporam reflexôes de natureza moral sobre a vida humana e os seus contextos que, de algum modo, sustentam a rede argumentativa dos respectivos paratextos, quando evocam Sá de Miranda, certamente também na prática de uma poesia de carácter sentencioso, veiculando, nas palavras de Maria Lucília Gonçalves Pires, «idêntica lição de prudência e temperança, e uma sabedoria construída sobre uma visão pessimista do homem e da sociedade» ${ }^{30}$. E se a maioria destas composiçóes incorpora "A Sanfonha de Euterpe», não há dúvida que "A Viola de Talia» recolhe muita da poesia dita «circunstancial», eivada, muitas vezes, por referências a falta de cartas de amigos, a pequenos favores não retribuídos, a promessas não cumpridas, acentuando uma dimensão da sociabilidade cortesã a que estas composiçóes não são alheias e que certamente contribuiu para perceber porque comportam mais «desengano», embora não ignorem, na brevidade de muitas delas, modos de concretizar a "agudeza»"

Em todo o caso, talvez possa aceitar-se que a relativa concentração de versos expressamente ditos "amorosos», nas primeiras três musas, permite considerar a hipótese de que os poemas em que o amor se faz tema nuclear se deveriam mais ao "artifício», no sentido de uma prática poética tida como "exercício de dizer», muitas vezes «à maneira de», e daí a referência explicita a "que de todo lo ageno estilo no es poco precioso el robo que hemos hecho [...] Lo candido de los Vegas, lo severo de los Leonardos, lo culto de los Góngoras y Ortensios [...]", texto que, como é sabido, já se encontrava na edição de 1649. De resto, a lógica argumentativa desse prólogo deixa perceber essa alusão a um exercício poético, quando evidencia a ligaçáo - ainda que ténue, em termos discursivos -, a um estado de juventude sensível ao aplauso e ao reconhecimento: «Residía allá entonces, cuando a los consonantes fue afable el aplauso. Yo era mozo, deseábale» ${ }^{32}$.

${ }^{28}$ Emanuele Tesauro, Il Cannocchiale aristotélico. "Trattato della metafora», capitolo VII, p. 267.

${ }^{29}$ J. A. de Carvalho, «Aspectos do desengano e da aceitação da vida em D. Francisco Manuel de Melo», sep. de Brotéria, vol. LXXVIII (1964), pp. 277-291 e 423-438 e "Poesia de circunstância e circunstâncias sociais» in Francisco Manuel de Melo, Obras Métricas. Dir. por Maria Lucília Gonçalves Pires e José Adriano de Freitas Carvalho. Braga: APPCDM, 2006, pp. LI-LXIV. Maria de Lurdes Correia Fernandes, «O Tempo do Desengano. Das aparências da vida à verdade da morte nos Relógios Falantes de D. Francisco Manuel de Melo", Peninsula. Revista de Estudos Ibéricos, n²2, (2005), pp. 343-364.

${ }^{30}$ Maria Lucília Gonçalves Pires, «Ecos literários nas Obras Métricas», Obras Métricas, p. XXVIII.

${ }^{31}$ José Adriano de Freitas Carvalho, «Poesia de circunstância e circunstâncias sociais», Obras Métricas, p. LXIV.

32 Obras Métricas, p. 13. O facto de Talia ser a musa da comédia justificava, certamente, a integração destes poemas criadores de "cenários», eivados de uma suave ironia marcada pelo «desengano». Ver sobre as musas, no 
Uma leitura, ainda que rápida, dos «Sonetos amorosos» e dos «Madrigais» de «El Arpa de Melpomene» detecta imediatamente o uso de um «saber» que releva simultaneamente da «erudição», pelo conhecimento de um leque temático tributário do «amor», e da já referida técnica retórico-compositiva, reveladora de um virtuosismo que adequa «subtis ideias, raridade... de palavras, frequência de agudos conceitos, ornados de razóes pomposas»" ${ }^{33}$. Um «artifício» que não dispensava a eufonia, o ritmo métrico e alguma ostentação de capacidade para verter o tema em esquemas estróficos diversos, no seio de um cânone clássico, antigo e novo, que se vai configurando, nas consequências do Renascimento, em temas, formas e conteúdos, desafiando a capacidade de inventio, a composição e a dispositio face aos modelos antigos.

No conjunto de "Sonetos amorosos», de «El Arpa de Melpomene», D. Francisco evidencia uma capacidade de construção, verso a verso, tema a tema, quase como prova de um trabalho aturado, resultante do estudo, de muitas e variadas leituras, como se tecesse uma tela de múltiplos e diferentes fios, atestando um virtuosismo poético que, efectivamente, parece, como registavam os editores, relevar mais do «artifício», no sentido da erudiçáo e da técnica, que do «desengano». Neste vasto grupo de sonetos, o poeta percorre a escala dos diferentes temas proporcionados pela pauta amorosa, como se de um pequeno "cancioneiro" se tratasse, no quadro de alguma sintaxe textual, e não deixa de chamar a atenção o facto do primeiro soneto do grupo, "Con sus versos», sintetizar uma espécie de programa poético inicial de temática amorosa, com alguma função prologal de relação autor/leitor: o autor solicita às suas «Letras, lenguas de amor menos dichosas» que pronunciem as suas «verdades ofendidas», antecipando um itinerário de «dulces afectos y ansias rigurosas, /suspiros mudos, quejas comedidas»" ${ }^{34}$. Náo se trata, efectivamente, de uma "história de amor» ou de "amores», no sentido da imitatio vitae, numa espécie de biografia poética forjada, mas de um conjunto em que as Lísis, Elisas, Cíntias, Filis, Célias, Amarílis, Clóris, Gerardas... facultam o exame da paixão amorosa, numa moldura em que o amor é «artifice ingenioso» e em que o poeta diz: «Lhoro, espero, obdezco y desconfío, / creo, dudo, prometo y dificulto» ${ }^{35}$. A beleza da dama, os seus olhos, as ondas douradas do seu cabelo, na lição de matriz petrarquista aprendida em Garcilaso, Sá de Miranda, Camóes ou Gôngora ${ }^{36}$, espraiam-se por estes «sonetos amoroso» que não ignoram a mudança e o fluir do tempo, acenando a uma perenidade que mantém escrita nas ruínas «tu nombre inmortalmente impreso ${ }^{37}$, o diálogo da memória e do silêncio ${ }^{38}$, o sofrimento amoroso, pela prática da

conjunto de uma ampla bibliografia, Júlio Vélez-Sainz, El Parnaso español: Canon, mecenazgo y propaganda en la poesia del siglo de oro. Madrid: Visor Libros, 2006, cap. I. «Peregrinación al Parnaso español (historia cultural del Parnaso), pp. 29-60.

${ }^{33}$ Jean Colomès, Le dialogue "Hospital das Letras» de D. Francisco Manuel de Melo. Texte établi d'après l' édition princeps et les manuscrits, variantes et notes. Paris: Fundaçăo Calouste Gulbenkian - Centro cultural Português, 1970, p. 15.

${ }^{34}$ Obras Métricas, p. 53

${ }^{35}$ Obras Métricas, p. 53.

${ }^{36}$ M. Lucília Gonçalves Pires, «Ecos literários nas Obras Métricas» in D. Francisco Manuel de Melo, Obras Métricas, ed. cit., pp. XXIII-XXVIII.

${ }^{37}$ Obras Métricas, p. 57.

${ }^{38}$ Obras Métricas, p. 58. 
eckfrasis, fazendo, como Garcilaso na égloga III, ao descrever, nas margens do Tejo, tapetes bordados pelas ninfas ${ }^{39}$. E ainda a ausência, a tristeza ${ }^{40}$, a instabilidade da fortuna ${ }^{41}$, a suspeita, a noite e a aurora, mas também alguma circunstancialidade como marca de uma produçáo poética de cariz cortesão: «Mandóse celebrar, por ley, la hermosura de dos señoras que concurrieron juntas a un balcón, sin preferir ninguna ni hablar de amor» ou «Peinábase la dama $»^{42}$. Existe amor correspondido, amor negado, amor esquecido, a passagem inevitável e obsessiva do tempo, a efémera beleza feminina (Viéndose mujer la que se vió niña) ${ }^{43}$, mas também a barroca «ocasiáo», a fonte, a abelha e, esporadicamente, a rosa ${ }^{44}$. O lirismo de D. Francisco não é como o de Camóes, um lirismo de memória em que passado e presente se confrontam, muitas vezes dolorosamente, numa espécie de diálogo de longa duração. Nem se encontra em D. Francisco a temática da "transformação dos amantes», apesar das diferentes alusões aos olhos das várias figuras femininas, umas vezes luminosos, outras de lágrimas cheios. Nem a imagem da amada pintada ou reflectida na alma do amante, nem sequer o tão ficiniano tema da imagem que se grava e difunde através do sangue que a transporta a todos os membros do corpo. Grande parte dos «Sonetos Amorosos» de «El Arpa de Melpomene» interrogam a figura feminina, criando o cenário de um diálogo em que o poeta pergunta, explica, pede, repetindo um conjunto de temas que apresenta sob formas lexicais diversas, prova de um virtuosismo poético que parece querer pôr-se à prova.

E embora a temática do amor se encontre, como se disse, também em sonetos, odes, canções e décimas dispersos por outras musas - de «A Tuba de Calíope», a "A Lira de Clío» pertencentes, respectivamente às segundas e terceiras musas, é nas primeiras que converge a maioria de composiçóes directamente identificada como tal e, sobretudo, é aqui que existem dois núcleos articulados de versos assim qualificados: os oitenta e dois «Sonetos Amorosos», em «El Arpa de Melpomene», os dezanove «Amorosos» romances de «La cítara de Erato», os oito «madrigais» de "La Tiorba de Polymnia» e um conjunto de «Décimas», «coplas» e «letrillas» da mesma musa em que a temática amorosa também prevalece, num grupo que integra apenas seis «décimas» mais circunstanciais ${ }^{45}$, num conjunto de vinte, uma "Letrilla Al Santísimo Sacramento» ${ }^{46}$ e outra «De los Reys» ${ }^{47}$ em nove e ainda doze quintilhas. Neste sentido, parece claro que a produção que faz do amor tema central se encontra en «Las Três

39 Obras Métricas, p. 61, Soneto LXXXIV. Sobre a Egloga III de Garcilaso, Aurora Egido, «El tejido garcilasista en la Egloga III», De la Mano de Artemia, pp. 81-97.

${ }^{40}$ Obras Métricas, p. 66.

${ }^{41}$ Obras Métricas, p. 68.

42 Obras Métricas, p. 83.

${ }^{43}$ Obras Métricas, p. 86.

${ }^{44}$ Vítor Aguiar e Silva, Maneirismo e barroco na poesia lírica portuguesa. Coimbra: C.E.R., 1971, pp. 398468. Maria Lucília G. Pires, Poetas do periodo barroco. Lisboa: 1985, pp. 32-39.

${ }^{45}$ Décimas XXXV, "A D.A.D.M. por unos versos con que alabó un tiro del P. su seńor»; Décimas XXXVI, "Toreó un caballero, su nombre Aries [...]»; Décimas XXXVII, «A la fábula de Cipariso [...]»; Décimas XXXVIII, «En alabanza del libro, Amores divinos [...]»; Décima LI, «En devoción de animas»; Décima LII, «Favor de una banda de humo $[\ldots]$ ».

${ }^{46}$ Letrilla LVII, Obras Métricas, pp. 322-323.

${ }^{47}$ Letrilla LVIII, Obras Métricas, pp. 324-326. 
Musas del Melodino y primera parte de sus versos» em núcleos não apenas identificados como «amorosos», mas, mesmo quando assim não é, em conjuntos que a mesma temática torna homogéneos em termos de funcionalidade, no contexto da sintaxe organizativa das Obras Métricas, como se os "primeiros versos", que o autor aproxima - não importa, neste contexto argumentativo, se com razão - dos anos de juventude, do tempo de "exercício» de imitação de outros poetas, relevassem mais do universo do "artifício», no sentido de um trabalho poético que procurasse um domínio perfeito das estratégias de «dizer», uma espécie de exercício cortesão, de prova de aptidão para uma produção poética amorosa de matriz palaciana, que acaba por ter uma espécie de contraponto em textos como a Carta a D. António Álvares da Cunha, na ocasião de seu casamento, inserta em «A Sanfonha de Euterpe» ${ }^{48}$ :

\footnotetext{
Quem levado dos enganos

Busca a mulher por prazer,

Em passando os verdes anos

Váo-se os bens ficam os danos,

Foge o amor, fica a mulher.
}

Mas quem por regras morais

Da cristã filosofia

Ama e escolhe os bons sinais,

Gosto e amor crece entáo mais

Quanto crece a companhia.

Ar sereno, vista pura,

O rosto belo e prezado, mal pecado, pouco dura;

Buscai n' alma a fermosura,

Nunca sereis enganado.

A temática amorosa parece, assim, relevar de uma «arte de palácio», ritualizada, muito próxima, em termos de concepção, dessa difícil «Arte da Galanteria» de D. Francisco de Portugal que Manuel de Melo tanto admirava: «Que hacer una copla era entendimiento, y muchas es parto de necedad [...], el galan no ha de ser poeta, mas ha de hazer versos, aunque no sea màs que por no pedillos emprestados $[\ldots] »^{49}$.

Desse ponto de vista, é uma produção poética muito inscrita no seu tempo, nos dias do viver palaciano de um grupo a que D. Francisco sempre se orgulhou de pertencer e também da prova textual evidente da integração numa República das Letras perfeitamente transnacional. Aliás, a linguagem codificada destes versos de amor, que não era para todos, mas para os que pertenciam aos círculos áulicos, como detentores de um saber que passava também pela aptidão e capacidade de construir composiçóes poéticas de temática amorosa, não deve desligar-se de uma espécie de "campo poético» comum a esses grupos e daí que muitas dessas

\footnotetext{
${ }^{48}$ Obras Métricas, p. 588. "A Dom António Alviz da Cunha na ocasiâo do seu casamento».

${ }^{49}$ D. Francisco de Portugal, Arte de Galanteria. Lisboa: En la Emprenta de Ivan de La Costa, 1652, p. 71.
} 
composiçóes pareçam efectivamente relevar mais do «artifício», como diziam os editores das «Segundas três Musas», na acepção do elaborado, de uma «agudeza» gracianesca, ou como dirá Emmanuele Tesauro, numa espécie de expansão do título de Il Cannocchiale Aristotélico, de «l' ldea dell'arguta et ingeniosa elocutione che serve à tutta l'Arte oratoria, Lapidaria e simbolica». Por tudo isso, estas composições merecem ser revisitadas, ainda que não pareçam tão envolvidas por aquele pessimismo antropológico, para usar uma expressão de Maria Lucília Gonçalves Pires, que torna outras obras mais atractivas, pela mundividência, pela náusea do fluir do tempo, ou, na muito presente poesia "sacra», pelo arrependimento, pela culpa, pela preocupação com a salvação ou ainda, na poesia que José Adriano de Carvalho designou como "circunstancial», com o quotidiano, com a rede de relaçôes, também clientelares, feita de parentes, amigos ou conhecidos.

Esta poesia em que o amor se faz tema - hoje de difícil leitura - porque joga simultaneamente na produção e recepção do conceito, identificando, por vezes, um com outro à primeira vista inconciliável, comporta um duplo processo que vela e desvela, fragmenta e reúne, quase obrigando o leitor a participar da capacidade inventiva do autor, experimentando o prazer decifratório, para citar de novo Tesauro, «d'involar col proprio ingegno cio che l'ingegno altrui furtivamente nasconde». $\mathrm{O}$ «engenho» exibido com a novidade das invençôes e a consequente maravilha do leitor são quase privilégios aristocráticos de um grupo que, na afirmação dos ideais de corte, identifica a superioridade intelectual e cultural da consciência literária, chamemos-lhe assim, para simplificar, com a hegemonia social e o nascimento. 
Série

Documentos

Imprensa da Universidade de Coimbra

Coimbra University Press

2010

- U

C • 